\title{
Study on the Current Situation and Improvement Mechanism of Comprehensive Management of Rural Human Settlement Environment in Dazhou
}

\author{
Xiaoyi Liu, Zibiao Cheng \\ School of Finance and Economics Management, Sichuan University of Arts and Science, Dazhou, China \\ Email:1xy_423@163.com
}

How to cite this paper: Liu, X. Y., \& Cheng, Z. B. (2020). Study on the Current Situation and Improvement Mechanism of Comprehensive Management of Rural Human Settlement Environment in Dazhou. Open Journal of Social Sciences, 8, 91-99.

https://doi.org/10.4236/jss.2020.811009

Received: October 13, 2020

Accepted: November 9, 2020

Published: November 12, 2020

Copyright $\odot 2020$ by author(s) and Scientific Research Publishing Inc. This work is licensed under the Creative Commons Attribution International License (CC BY 4.0).

http://creativecommons.org/licenses/by/4.0/

(c) (i) Open Access

\begin{abstract}
Under the guidance of the Rural Revitalization Strategy, the comprehensive management of rural human settlement environment is an important path to promote the modernization development of rural areas in Dazhou and make rural people feel happy and satisfied. Therefore, it is necessary for Dazhou to explore the sustainable development strategy of comprehensive management of rural human settlement environment, so as to effectively optimize the rural human settlement environment. Based on the analysis on and discussion about the current situation of comprehensive management of rural human settlement environment in Dazhou, this paper analyzes the difficulties existing in the comprehensive management of rural human settlement environment in Dazhou, such as insufficient construction of supervision mechanism, lack of management funds, lack of complete infrastructure, weak awareness of environmental protection of villagers, and lack of the construction of talent team. It is proposed that for rural human settlement environment management in Dazhou we should establish the long-term management mechanism, system construction mechanism, constraint incentive mechanism, village self-management mechanism, university linkage mechanism and other improvement mechanisms, in order to realize the overall improvement of rural environment.
\end{abstract}

\section{Keywords}

Rural Human Settlement, Comprehensive Management, Improvement Mechanism

\section{Introduction}

2020 is the last year of the three-year action for the implementation of the rural 
human settlement management. In order to thoroughly implement the important instructions of General Secretary Xi Jinping on improving the rural human settlement environment, on the rural working conference of the Dazhou $\mathrm{Mu}$ nicipal Committee in 2019, it was clearly pointed out that in 2019 the domestic sewage in more than $50 \%$ of the administrative villages was effectively treated; in 2020 the domestic waste in more than $90 \%$ of administrative villages would be effectively disposed of; in 2019 the popularizing rate of sanitary toilets for rural users in the whole city was above $70 \%$ and there was a public toilet in every administrative village, and in 2020 the comprehensive utilization rate of fecal residue and waste water would be above $75 \%$. There is still a certain gap between Dazhou and Sichuan Province in terms of rural human settlement management objectives, such as the treatment rate of rural domestic sewage and popularization rate of toilet. Therefore, the systematic and comprehensive research is of great practical significance.

\section{Current Situation of Development of Comprehensive Management of Rural Human Settlement Environment in Dazhou}

By the end of December 2019, Dazhou has 315 towns (townships and subdistrict offices). It is a county with a large population and an agricultural county in Sichuan Province. It has jurisdiction over 4 counties, 2 districts and 1 city. There are a total of 8 subdistrict offices, 106 towns and 201 townships. The permanent resident population of Dazhou is 5.741 million, of which the rural population is $3,034,700$, accounting for $52.86 \%$. Dazhou has a large proportion of rural population. The task of rural human settlement management is tough.

\section{1) Strengthen the rural sewage treatment}

Dazhou is fully aware of the importance and urgency of promoting rural sewage treatment. First, it takes accurate measures and implements orderly; second, it integrates resources and solves the fund problem; third, it monitors the transportation process and intelligently maintains. After a series of measures were taken, by 2019, in the whole city the construction of sewage treatment system in 10 key towns has been completed, and 10 sewage treatment demonstration villages will be built. By 2020 , the domestic sewage will be treated in about $50 \%$ of administrative villages in the whole city, the rural domestic sewage treatment and black and odorous water body treatment tasks in key areas such as the banks of main streams and tributaries of Qu River and drinking water source protection zones will be completed, and there will be sewage treatment facilities in every town and township.

\section{2) Promote the domestic waste treatment}

In order to strengthen the management of rural domestic waste in Dazhou, create clean and tidy villages and improve the rural human settlement. First, the collection and treatment mode of domestic waste is improved. The waste collection, transportation and treatment mode of "household collection, village collec- 
tion, town (township) transportation and county treatment" is further promoted, and the construction of waste classification and the construction of collection, storage and transportation facilities are promoted throughout the region. By the end of 2019, the rate of cleaner in the village group of administrative village in Dazhou has reached $100 \%$.

Second, on-site classification and resource utilization of domestic waste are promoted. By the end of 2019, the rural domestic waste classification (Figure 1) has been implemented in every village in Dazhou and the proportion of villages with effective treatment of domestic waste is above $75 \%$. More than $90 \%$ of administrative villages will realize effective treatment of domestic waste by 2020 .

Third, the management of rural domestic waste stock is carried out. The treatment of waste mountains and villages and dams surrounded by waste are focused on. The domestic waste, construction waste and white pollution accumulated in rural areas are cleared first, and all kinds of waste such as urban waste are prevented from going to the countryside.

\section{3) Carry out the manure treatment in the toilets}

In order to comprehensively improve the sanitary conditions and service level of toilets in our city and effectively improve the human settlement environment in urban and rural areas, Dazhou assigned the target task of new construction and reconstruction of toilets from 2018 to 2020 according to the provincial standard. First, the manure treatment is strengthened, the management and maintenance level is raised, the toilet drainers are kept unobstructed, the ponds of manure are kept closed, slag is regularly removed and transported in a timely manner for septic tanks, and the pipes are immediately dredged in case of blockage. Second, advanced experience is learned from, the change of biogas digester into toilet is actively explored, small and medium-sized centralized sewage treatment facilities with village as the unit or integrated treatment equipment of domestic sewage and feces with household as the unit are promoted according to

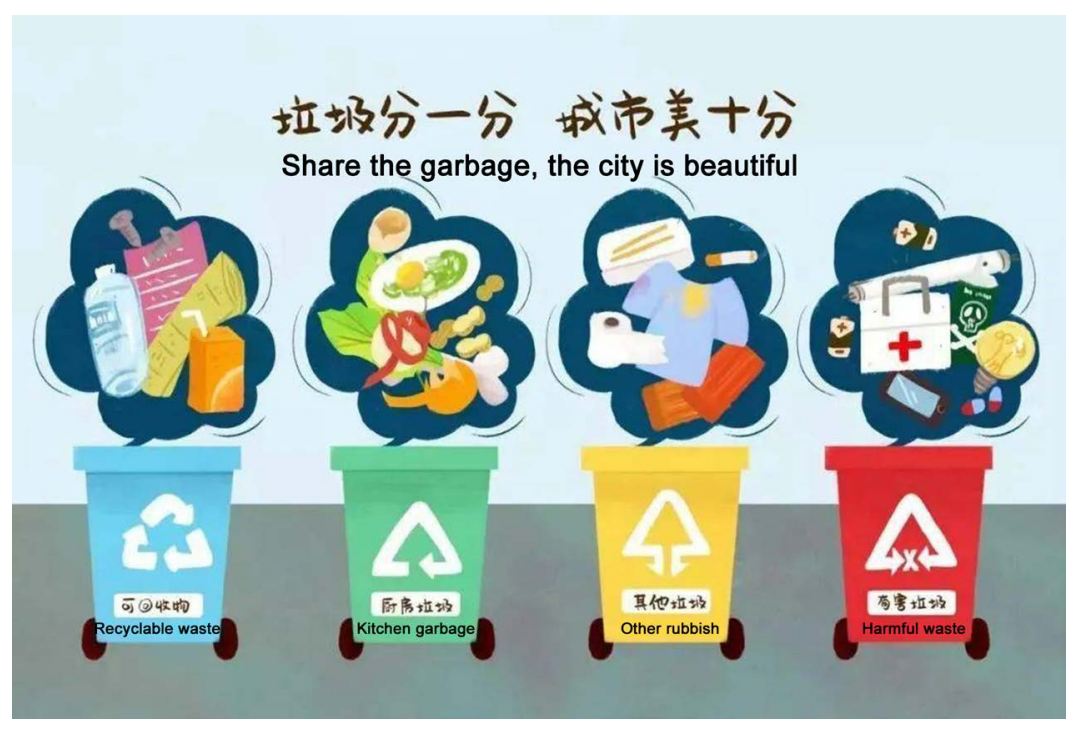

Figure 1. Classification of garbage in Dazhou. 
local conditions. Third, the construction of rural household toilets is further promoted. According to the ideas of adjusting measures to local conditions, centralizing and being closely grouped, promoting in the whole village and long-term operation, the management of rural human settlement and the construction of livable villages are integrated, and the construction and transformation of rural household sanitary toilets are accelerated (Yu \& Hao, 2019). By the end of 2019, 548 rural public toilets and 218,000 rural household toilets have been newly built or reconstructed, the popularizing rate of rural sanitary household toilets have reached $61 \%$, and 15,000 rural household toilets have been newly built or reconstructed.

\section{4) Promote the construction of rural civilization}

In recent years, around the construction of rural civilization, Dazhou has deeply promoted the construction of civilized villages and towns and "Four Good Villages" (Four Good: Live in a good house; Live a good life; Develop good habits; Form a good atmosphere), established the filial piety culture and education base, opened the moral lecture hall, organized the activities of Folk Culture Festival, Day for Respecting the Aged, selected moral models, "Star Civilized Households", "Good Daughter-in-law", "Good Mother-in-law", etc. In all families in the city, good family tradition is cultivated and good family precepts are delivered, and socialist core values are further cultivated and practiced. The guidance of public opinion and social atmosphere of transforming social traditions, civilization and frugality are actively created. New-style wedding, simple funeral and no activity for minor matters are vigorously advocated. High-profile "weddings and funerals", extravagance and waste, comparing with each other and other unhealthy phenomenon are effectively avoided. The healthy atmosphere of the society is constantly carried forward and the level of social civilization is further raised.

\section{5) Promote village planning and management}

According to the requirements of spatial planning, Dazhou connects and integrates the original village planning, village construction planning, land use planning of village, land consolidation planning and other rural planning, the compilation of village planning is comprehensively promoted, and the full coverage of village planning management is promoted. According to the requirements of "integrating multiple planning", Dazhou will complete the rural construction planning of Tongchuan District, Dachuan District, Dazhu County, Quxian County and Kaijiang County, and make more than 1,000 characteristic and practical village plans. By 2020, the task of compilation of characteristic and practical village planning will be basically completed, and the coverage rate of administrative village planning and management will be above $80 \%$. The villages and towns of Dazhou consider rural revitalization and improvement of rural human settlement as the ultimate goal, adhere to the principle of "no construction or investment without planning", and strengthen the management of village planning. Once approved, the village planning must be strictly implemented. No department or individual is allowed to modify or change it illegally. 


\section{Real Difficulties of Comprehensive Management of Rural Human Settlement Environment in Dazhou}

Although Dazhou has made a lot of achievements in the comprehensive management of rural human settlement environment, its achievements are still far from those in the rural areas of the whole province or developed areas and the expectations of farmers. The comprehensive management of rural human settlement environment in Dazhou has the following real difficulties:

First, the construction of supervision mechanism is insufficient. The management of human settlement environment relies on administrative control means. However, the environmental protection agencies at the county level still lack the supervision and implementation ability, and there is no management subject at the town and village level, which affects the solution of environmental problems (Xu, 2020). Although the government has issued some treatment measures for waste and domestic sewage, such as providing cleaners in each village and transferring waste in a centralized way, they are not taken in the administrative villages. The waste is burned by the villagers themselves, causing secondary pollution.

Second, management funds are insufficient. At present, the funds for human settlement environment management in Dazhou are seriously insufficient, the multi-channel financing system has not been constructed, and the government's existing project funds cannot meet the actual construction needs, which affects the smooth implementation of environmental management projects. On the one hand, in terms of financial investment of the government, the funds for environmental sanitation facilities are insufficient. On the other hand, in terms of self financing of villages, a lot of rural areas in Dazhou are below the poverty line, and most of the rural villages are short of collective funds, rural collective funds belong to all the villagers, which is an important material basis for the development of rural economy and the realization of common prosperity of farmers. However, according to the author's investigation, more than $70 \%$ of administrative villages in Dazhou have no collective funds or only a small amount of collective funds. They do not have collective income. Due to the low income of farmers, it is difficult to raise funds for rural construction.

Third, there is a lack of complete infrastructure. There is a big gap in Dazhou in terms of rural domestic waste treatment facilities, non-hazardous sanitary household toilets, domestic sewage treatment facilities, public lighting facilities and other infrastructures. The local government's ability to provide the environmental protection facilities is much lower than the living demands of rural residents. In the construction of waste facilities, local government has insufficient functions in the construction of local infrastructures. Especially the collection and transportation facilities are simple and crude, thus affecting the waste disposal rate, sewage recovery rate and other indicators. It is not good for the raising of the management level of human settlement environment.

Fourth, the villagers' awareness of environmental protection is weak. Most of 
the rural villagers in Dazhou have weak awareness of environmental protection. They are against the environmental management and lack awareness of environmental protection. Many villagers believe that this activity is an image project of leading cadres at the grass-roots level. They do not actively participate in and respond to this activity. They litter everywhere and do not take good care of public facilities, which further increases difficulties of the management of human settlement environment.

Fifth, there is a lack of the construction of talent team. At present, the hollowing out of villages and the weakening of collective economy of village in Dazhou have become the primary problems restricting the development of rural construction. The rural left-behind population is small. Most of them are the elderly and children, and many young and middle-aged labor forces choose to work in other places. There are difficulties in improving the human settlement environment.

\section{Improvement Mechanism of the Comprehensive Management of Rural Human Settlement Environment in Dazhou}

First, the trinity working mode shall be innovated and a long-term management mechanism shall be established. First, starting from the management and protection mechanism, the construction of rural professional cleaning team and the consolidation and implementation of the long-term management and protection mechanism shall be promoted (Zhang, 2019). Second, starting from the fund guarantee mechanism, the government shall coordinate all kinds of funds to strengthen the investment in the management of human settlement environment. A diversified investment guarantee mechanism of rural cleaning funds dominated by public finance of the government, raised by villagers' committees and villagers, paid by beneficiaries and supported by social funds shall be established. Finally, starting from the participation mechanism, the long-term guarantee for the leadership of grass-roots organizations, technical advantages of enterprises and strengthening of the management of rural human settlement environment shall be realized.

Second, the setting of specific executing agencies shall be refined and the institutional construction mechanism shall be improved. On the one hand, the grass-roots government shall set up a special leading group to play the role of organization, supervision and inspection, improve the construction of mechanism of division of labor, define the specific leaders in charge, adhere to the principle of "coordination and cooperation of departments and joint action of all parties", and implement the strip and block linkage and the combination of full-time and part-time staffs (Zou, 2020). Each shall perform his or her own duties. On the other hand, the construction of legal system shall be strengthened, local regulations and administrative provisions shall be improved, the relevant rural special environmental protection laws and regulations shall be established, and the illegal acts of breaking the rural ecological environment shall be strictly 
punished. The specific management systems such as regular meeting system, standing book system, information disclosure system, responsibility assessment and rewards and punishments shall be implemented. They shall restrain, encourage and supervise the behaviors of subjects relying on the system guarantee.

Third, the implementation of the supervision and guarantee system shall be promoted and the restriction and incentive mechanism shall be implemented. Governments at all levels shall actively perform their own functions; incorporate the society, market, collective organizations of villages, villagers and other subjects into the management mechanism of human settlement environment; define the distribution of rights and responsibilities of supervision subjects at all levels; realize personal responsibilities; establish a 3D supervision network chain; and create a working situation of multi-party participation and good interaction by realizing the multi-channel and open construction of management affairs with WeChat and network platform.

Fourth, the cultivation of villagers' self-government concept shall be strengthened and the mechanism of villagers' self-government shall be constructed. On the one hand, the construction of villagers' self-government organizations shall be promoted, villagers' opinions shall be widely solicited through open elections, the non-principle problems involved in the process of environmental pollution control shall be solved by democratic consultation, and a good social management atmosphere shall be created (Jiang \& Li, 2020). On the other hand, the publicity of environmental management shall be strengthened, the propaganda method popular which is loved by people and easy to understand shall be used to guide the villagers to establish the concept of self-management, a strong atmosphere of everyone's concern and household participation shall be created, and the effectiveness of rural human settlement environment management shall be improved.

Fifth, the goal of sustainable development of talents shall be achieved and the linkage mechanism of colleges and universities shall be built. The sustainable construction of management of the rural human settlement environment cannot be separated from talent guarantee. Therefore, the university talents shall be taken as the subjects and the linkage mechanism of university classroom shall be relied on for the innovation and sustainable development path of the management of human settlement environment. Specifically, a long-term cooperation relationship shall be established with local colleges and universities (such as Sichuan University of Arts and Sciences or Dazhou Vocational and Technical College), college students shall be guided to contribute creative ideas and innovative ideas for the management of rural human settlement environment, and the excellent results shall be applied to the actual work of rural environment management, so as to further provide intellectual guarantee and talent support for the management of human settlement environment.

\section{Conclusion}

In recent years, the importance of the management of rural human settlement 
environment in "Rural Revitalization" is gradually highlighted, and people's attention has also been greatly improved. More and more areas in Dazhou have explored the management of rural human settlement environment and achieved some results. Nowadays, the people's yearning and demands for a better life are higher and higher. Therefore, the management of rural human settlement must start from reality. We should not only focus on a few typical villages, demonstration villages and model villages, but also pay attention to each administrative village in Dazhou and establish a systematic and complete improvement mechanism, so as to realize the overall improvement of rural environment. Therefore, facing the existing problems, villages, the society and the government shall interact positively and manage jointly. The initiative, enthusiasm and coordination of governments at all levels, village committees and villagers shall be improved. The rural methods shall be adopted, including the establishment of basic principles, working paths, financing construction and technical models suitable for rural areas. We shall adjust measures to local conditions, take measures suitable for the village, and try our best according to our ability. However, we shall not use the one-size-fits-all approach, achieve effective results step by step, and make the long-term contributions, so that villages can be clean, green, beautiful and cultural and the goal of beautiful rural construction can be achieved.

Rural construction is an eternal development theme, but this paper is not comprehensive enough to investigate the situation of rural governance in Dazhou, and the improvement mechanism stays at the theoretical level. I hope that the follow-up research on such problems can put forward some operational countermeasures and suggestions.

\section{Fund Project}

This paper is a project funded by Sichuan Old Revolutionary Base Area Development Research Center in 2020 (Sichuan and Shanxi Old Revolutionary Base Area Revitalization Research No. SLQ2020CA-01); this paper is a project funded by Sichuan Old Revolutionary Base Area Development Research Center in 2020 (No. SLQ2020SB-02); and this paper is a project funded by Dazhou Federation of Social Science in 2020. This paper is an innovation team support project funded by rural revitalizationary performance evaluation of Sichuan Old Revolutionary Base Areas in the new era.

\section{Conflicts of Interest}

The authors declare no conflicts of interest regarding the publication of this paper.

\section{References}

Jiang, W. J., \& Li, N. (2020). Path of Comprehensive Management of Rural Human Settlement Environment in Hebei Province under the Strategy of Rural Revitalization. $\mathrm{Fu}$ jian Tea, No. 2, 284.

$\mathrm{Xu}$, J. R. (2020). Study on the Problems and Countermeasures of the Improvement of 
Rural Human Settlement Environment-A Case Study of Area L in Sichuan Province. Rural Economy and Science and Technology, No. 13, 294-295.

Yu, F. W., \& Hao, X. B. (2019). Current Situation of Research and Prospect of the Management of Rural Human Settlement Environment. Ecological Economy, No. 10, 167-170.

Zhang, X. (2019). Exploration on the Construction of Long-Term Mechanism for Comprehensive Management of Rural Human Settlement Environment. New West, No. 10, 60.

Zou, L. Q. (2020). Case Study on "Seven Changes" of the Management of Rural Human Settlement Environment in Pujiang County. Chengdu. Master Thesis, Chengdu: University of Electronic Science and Technology of China. 